\title{
Explaining the Stock-Stock, Bond-Bond and Stock-Bond Correlation Across Countries
}

\author{
David G McMillan \\ Division of Accounting and Finance \\ University of Stirling
}

October 2019

Revised April 2020

\begin{abstract}
This paper examines the behaviour of the same asset-cross country and cross-asset same country correlations for stocks and bond for four (Germany, Japan, UK, US) major economies. Using the realised volatility methodology to construct time-varying correlations, the results reveal that rising same asset correlations occur when cross-asset correlations fall. While there is evidence of segmentation of Japanese assets within international markets. We seek to explain the movement in correlations and note that the variables that exhibit a positive predictive relation for the stock-bond correlation, exhibit a negative predictive relation for the stock-stock and bond-bond correlations and that this is linked to economic conditions. Within this, four variables (inflation, stock returns, consumer sentiment and purchasing managers index) exhibit consistent significance across the regressions. Using these variables, we construct a correlation indicator variable that is used to construct a switching portfolio. This constructed portfolio constructed outperforms buy-and-hold alternatives.
\end{abstract}

Keywords: Stocks, Bonds, Correlation, Predictability

JEL Codes: C22, G12

Address for Correspondence: Professor David McMillan, Accounting and Finance Division, University of Stirling, FK9 4LA

Telephone: +44(0)1786-467309 Fax: +44(0)1786-467308

E-mail: david.mcmillan@stir.ac.uk 


\section{Introduction.}

Understanding the drivers of the correlations across financial markets and countries is important to investors in building efficient portfolios, to policy-makers in understanding how shocks are transmitted across markets and to academics and those engaged in modelling financial market behaviour. This paper uses a set of predictor variables to model the stockstock, bond-bond and stock-bond returns relation across a set of major international economies. While there exists an active literature examining the movement of correlations between these assets, notably, the stock-stock and stock-bond relations, there is little consensus on their key drivers. Moreover, existing research typically (although with exceptions) only considers the nature of the interactions between one set of financial assets, most commonly, the cross-market stock return relation. This paper will consider the nature of the three relations, stock-stock, bond-bond and stock-bond, to examine any commonality in the drivers of these relations or whether their movements are governed by different specific factors.

The stock-stock return relation across countries is one that is extensively studied, including notable work by, for example, Bekaert and Harvey (1995), Bekaert et al (2002), Forbes and Rigobon (2002) and Bekaert et al (2005). The bond-bond return relation has been less studied but key work includes, Barr and Priestley (2004), Skintzi and Refenes (2006) and Kim et al (2006a). The emergent consensus from this literature is that correlations for the same asset across international markets have risen over time. The literature regarding the stock and bond return correlation has reached less of a consensus. Within this line of research there exists evidence that supports a positive relation between stock and bond returns, this includes the work of Barsky (1989), Shiller and Beltratti (1992) and Campbell and Ammer (1993). Equally, work has noted a negative correlation between these assets, including Gulko (2002), Connolly et al. (2005) and Andersson et al (2008). Indeed, the prevailing view is that the nature of the correlation is time-varying, with a positive correlation under normal market conditions 
subsumed by a negative correlation arising from flight-to-safety effects during crisis periods. In seeking to understand the dynamics of this relation, a series of papers (e.g., Baele et al, 2010; Aslanidis and Christiansen, 2012,2014) consider a range of macroeconomic and financial explanatory variables. In an attempt to develop a unified stock and bond asset pricing model, Li (2002) argues that the source of different shocks will lead a change in correlations, with interest rate shocks resulting in a positive relation and dividend or inflation shocks leading to a negative correlation.

In work with a more direct relation to this paper, Kim et al (2006b), Connolly et al (2007) and Baur (2010) consider how the same asset-cross country and cross asset-same country relations interact. Kim et al (2006b) examine the effect of European monetary union on the nature of correlations both within and across stock and bonds markets. While reporting generally higher same asset correlations, they report a downward trend in cross-asset correlations driven by a flight-to-safety effect. Connolly et al (2007) note an inverse relation of the stock-stock and the stock-bond return correlations in response to changes in stock market uncertainty. A higher value of the implied volatility index leads to higher stock return correlations but a lower stock-bond return correlation. Baur (2010) continues this theme and notes that a higher same asset-cross country correlation (labelled as contagion) occurs with lower cross asset-same country correlations (labelled as flight-to-safety). Baur argues that the inverse higher same asset correlation and lower cross asset flight-to-safety arises from increased portfolio rebalancing.

This paper combines these two general lines of research and seeks to explain the same asset-cross country and cross asset-same country correlations and any inverse relation that arises from the second research line, using a set of explanatory variables that have been typically considered in work modelling same asset international correlations, from the first line of research. We obtain the stock and bond correlations (cross country and cross asset) for 
Germany, Japan, the UK and the US using a realised correlation method, following the approach taken in Evans and McMillan (2009), Aslanidis and Christiansen (2012), Viceira (2012) and Campbell et al (2017). We then model these correlations using both macroeconomic and financial variables, including measures of output, inflation, interest rates and asset returns. This follows the work in, for example, Baele et al (2010), Aslanidis and Christiansen (2012, 2014), Viceira (2012) and Aslanidis et al (2019). We further extend the set of explanatory variables to include measures of confidence and uncertainty, including consumer sentiment, the purchasing managers index, financial conditions index from the Chicago Federal Reserve and economic policy uncertainty. Aslanidis et al (2019) also include measures of financial conditions and policy uncertainty when examining stock and bond relations. Phan et al (2018) argue that economic policy uncertainty can predict stock returns, while evidence that consumer sentiment predicts stock returns date back to Fisher and Statman (2003).

In preview of the results in this paper, they reveal support for a generally rising same asset correlation at the same time as a falling cross asset correlation, although the results for Japan show a degree of segmentation. In terms of explaining the movements in the correlations, four variables exhibit a consistent relation across the different regressions, namely, inflation, stock returns, consumer sentiment and the purchasing managers index. Moreover, these variables exhibit the opposite predictive relation across same asset and cross asset correlations. These results support the view that, in general, when the predictor variables indicate an expanding economy, this is associated with higher cross asset and lower same asset correlations, while when the variables indicate declining economic performance, this is associated with higher same asset and lower cross asset correlations. Further, we are able to use this information to construct a portfolio that invests across assets and countries based on the nature of the predictive relation that improves on alternative buy-and-hold portfolios. 


\section{Empirical Methodology.}

The dependent variable used in this paper is the correlation between stock returns across international markets, bond returns across international markets and between stock and bond returns within a market. A key issue, therefore, is how to construct the correlation series given that it is an unobserved variable.

An obvious approach in the construction of the correlation series is to use an extension of the GARCH (Engle, 1982; Bollerslev, 1986) model that allows for the joint modelling of asset returns variance and their covariance. Examples of this include, Baur and Lucey (2010) who use a multivariate-GARCH model and Colacito et al (2009) who use an extension of the DCC model of Engle (2002). A simpler approach is to use rolling windows for the correlation between two series. Fan and Mitchell (2017) use a 1-year and 5-year rolling window to illustrate the nature of time-variation, while Rankin and Shah Idil (2014) consider a variety of window lengths, in both cases for the stock and bond correlation. McMillan (2019) uses 1-year rolling windows for correlations across a range of assets. A more recent approach builds upon the realised volatility literature (see, McAleer and Medeiros, 2008 for a general review). Using this approach, realised measures for both volatility and covariance can be constructed and from these the realised correlation series is obtained. This approach is taken by Aslanidis and Christiansen (2012) for the stock and bond correlation, while Evans and McMillan (2009) consider both a GARCH and realised correlation approach to examine the co-movements across a wide range of international stock markets.

Thus, to calculate the time-varying correlation series, we implement the methodology that originated with the realised volatility approach. This approach uses higher frequency data to compute the lower frequency variable of interest. The advantage of this methodology is that it allows the correlation series to be regarded as an observable variable. Furthermore, this approach leads to a reduction in noise in the construction of the covariance and variance series, 
which allows for more accurate estimation. The use of the realised volatility approach largely began with Andersen and Bollerslev (1998), although its use pre-dates that, with French et al (1987) and Schwert (1989) both using daily data to construct monthly volatility series. Since, the work of Andersen and Bollerslev (1998), the use of higher frequency data in constructing lower frequency variables has become popular (see, for example, Andersen et al, 2003; McAleer and Medeiros, 2008). As noted above, the realised correlation is considered by Aslanidis and Christiansen (2012) and Evans and McMillan (2009), while Viceira (2012), Campbell et al (2017) and Aslanidis et al (2019) use the same approach to construct a similar series (the realised bond beta). The realised correlation is constructed from the realised variance, which is obtained by summing over the lower frequency, the squared returns of the higher frequency data and the realised covariance, which is obtained by summing over the lower frequency, the product of the two returns series of the higher frequency data. The realised variance and covariance series are thus generated as:

$$
\begin{aligned}
& \sigma_{i(j), t}^{2}=\sum_{d=1}^{M} r_{i(j), d, t}^{2} \\
& \sigma_{i j, t}=\sum_{d=1}^{M}\left(r_{i, d, t}^{2} r_{j, t, d}^{2}\right)
\end{aligned}
$$

where, $d$ refers to the number of days in a month, $M$ and $i$ and $j$ refer to the assets for which the series are constructed and refers to the stock and bonds returns. The realised correlation, $\rho$, series is then constructed as:

$$
\rho_{i j, t}=\sigma_{i j, t} /\left(\sqrt{\sigma_{i, t}^{2}} \sqrt{\sigma_{j, t}^{2}}\right)
$$

Having obtained the correlation series, we then consider a regression model designed to understand the key drivers for same asset-cross country and cross asset-same country correlations. Thus, we estimate:

$$
\rho_{i j, t}=\alpha+\sum_{k=1}^{K} \beta_{k} x_{k, t-1}+\varepsilon_{t}
$$

Where $x_{t}$ represent the $K$ explanatory variables, which are lagged one period and $\varepsilon_{t}$ is a random 
error term.

\section{Data and Empirical Results.}

\subsection{Data and Correlation Dynamics}

We obtain stock and bond return data from Datastream for Germany, Japan, the UK and the US. The data is obtained on a daily basis over the time period from the first day of 1980 (with the exception of Japanese bond data, which is only available from the first day of 1984) to the last day of May 2018. As discussed in Section 2, we construct monthly realised correlations for each of the cross-country stock-stock return and bond-bond return correlations, as well as the intra-country stock-bond return correlation. These correlations are plotted in Figure 1, while Table 1 presents summary statistics for these series.

To explain the movement in these correlation series, we utilise a set of explanatory variables that are considered as predictor variables either for asset returns or correlations within the current literature. In common with the work of Baele et al (2010), Aslanidis and Christiansen $(2012,2014)$ and Viceira (2012), we consider the growth rate of industrial production, the change in the consumer price index, the change in three-month Treasury bills, the term spread between ten-year Treasury bonds and three-month Treasury bill and the respective asset returns. Following, Aslanidis et al (2019) we extend the set of explanatory variables to include the economic policy uncertainty measure of Baker et al (2016), which is also used to explain movements in stock returns (e.g., Phan et al, 2018), and the Chicago Federal Reserve Financial Conditions index. Further, we capture household and business confidence by including the University of Michigan Consumer Sentiment Index and the Purchasing Managers Index.

In motivating this choice of explanatory variables, they are designed to proxy for economic conditions and risk, which will affect investor appetite for riskier stocks and safer 
bonds. Research has highlighted that correlations vary over time due to economic conditions and particularly downturns (e.g., Ang and Bekaert, 2002; Butler and Joaquin, 2002; Bekaert et al, 2005). Other research links changing correlations to uncertainty (e.g., Antonakakis et al., 2013; Aslanidis et al, 2019). Our chosen variables thus seek to capture both of these aspects. Figure 2 presents the plots of these series, which is also monthly and collected over the same sample period as the asset returns data, except for the economic policy uncertainty variable that begins in 1985 month $1 .^{1}$

Examining the summary statistics in Table 1, we can observe that the mean value of the stock and bond correlations are all close to zero, with the value for Japan also negative. The mean value of the same asset correlations are all positive and higher in magnitude than the stock-bond correlations. We can further note that the correlations involving Japanese assets are lower than those involving Germany, the UK and the US. Regarding the variability of the correlations, we can see that for all series, the minimum and maximum values straddle zero, implying significant time-variation. We can note that both the standard deviation and the minimum-maximum range of the cross-asset correlations are greater than the same asset correlations. Thus, there is greater variability in the stock-bond correlation than in either the stock-stock or bond-bond correlations.

An examination of Figure 1 also presents an interesting view. Taking the top row of graphs, which represent the stock and bond correlation, we can observe that for each series, the correlation fluctuates around a constant mean over (approximately) the first half of the sample before declining to fluctuate around a lower value in the second half of the sample. Moreover, in the first half of the sample, the correlations are predominantly positive, while over the second half of the sample, they are negative. This change in cross-asset correlation is consistent with

\footnotetext{
${ }^{1}$ The presented data is all US and thus our analysis takes the perspective of a US investor. However, we substitute with equivalent data for the German, Japanese and UK markets where it is available, with the results qualitatively unchanged.
} 
that reported by, for example, Fan and Mitchell (2017), Rankin and Shah Idil (2014) and McMillan (2019). Considering the same asset correlations for Germany, the UK and the US, we can see that, again, over the first half of the sample, the correlations fluctuate around a relatively constant value, while over the second half of the sample, the same asset correlations increase. This evidence of higher correlation is similar to earlier work (e.g., Baele, 2005; Berben and Jansen, 2005; Fratzscher, 2002; Tsai, 2014). Thus, when the cross-asset correlations decline, the same asset correlations rise. A similar result is noted by Baur (2010), who argues that contagion leads to higher same asset correlations, while a flight-to-safety effect leads to falling cross-asset correlations. Figure 1 also reveals that the same asset correlations involving Japanese assets fluctuate around zero and in contrast to other countries, exhibit no directional movement.

\subsection{Regression Results}

Table 2 presents the estimated results of equation (4) for correlations involving the US. ${ }^{2}$ The first column of results presents the estimated coefficients and significance tests for the stock and bond correlation, while the remaining results presents the equivalent values for the bondbond and stock-stock correlations. Examining the estimated results for the stock and bond correlation, we can see a positive and statistically significant relation with the lagged inflation rate, stock returns and consumer sentiment (with weaker $10 \%$ significance for industrial production growth and the term structure of interest rates). A negative and statistically significant relation is found with lagged short-term interest rate changes, bond returns and economic policy uncertainty. Thus, a higher stock and bond correlation is predicted by variables that would be associated with a growing economy, higher inflation and output growth,

\footnotetext{
${ }^{2}$ Residual tests are not reported for space considerations, but they support the use of the Newey-West corrected standard errors.
} 
a steepening of the term structure, increasing stock returns and growing consumer sentiment. Equally, a falling stock and bond correlation is predicted by variables that are consistent with an economic slowdown, higher policy-related interest rates, higher bond returns and increased uncertainty. Such a set of results can be regarded as consistent with the view that a negative stock and bond correlation is likely to be consistent with flight-to-safety behaviour.

Examining the same asset correlations, we first consider those involving the US with both Germany and the UK. For the bond return correlations, we can see a negative predictive relation arising from industrial production growth, inflation, the term structure, stock returns, consumer sentiment and the financial conditions index. Thus, for every variable that exhibited a positive relation with the stock and bond correlation, it now exhibits a negative relation with the bond-bond correlation. For the variables that exhibited a negative relation with the stock and bond correlation (bond returns and economic policy uncertainty), they now exhibit a positive relation with the bond-bond correlation, although not statistically significant. The only significant positive relation arises from the purchasing managers index (which is negative and significant at the $11 \%$ level for the stock-bond correlation). For the stock-stock correlations, we see the same picture. A negative predictive relation arises from industrial production growth (Germany only), inflation, the term structure, stock returns (Germany only) and consumer sentiment. Thus, this is the same set of variables that also produced a negative predictive relation for bond-bond correlations and a positive predictive relation for the stock-bond correlation. A positive predictive relation for the stock-stock correlations is found for the purchasing managers index (as with the bond-bond correlation) and economic policy uncertainty (UK only), which exhibited a negative predictive relation with the stock-bond correlation.

The correlations involving Japan depict a weaker picture in terms of the predictive relations arising from the explanatory variables. This is nonetheless consistent with the 
depiction in Figure 1 in which the bond-bond and stock-stock correlations involving Japan fluctuate around a relatively constant value. For the bond-bond correlation, there are no significant predictive relations, while for the stock-stock correlation, stock returns exhibit a negative relation (consistent with the results for the US-German stock correlation) and economic policy uncertainty exhibits a positive relation (consistent with the US-UK stock correlation). In each case, the explanatory power, measured by the R-squared value, is lower for the correlations involving Japan than for the other series.

The results presented here, in conjunction with the summary statistics in Table 1 and the plots in Figure 1 present an interesting conclusion. The time-varying nature of, and explanatory variables for, the cross-asset stock-bond correlation on the one hand and the same asset bond-bond and stock-stock correlations on the other exhibit an opposite nature. From Figure 1, we can observe that rising same asset correlations occur when cross-asset correlations are falling. In terms of the explanatory variables, we can see that a variable that exhibits a positive predictive effect on the stock-bond correlation, exhibits a negative predictive effect on the bond-bond and stock-stock correlations. The knowledge of such contrasting relations is important for both policy-makers in understanding the transmission of shocks and investors in building diversified portfolios.

Table 3 presents the equivalent results for Germany, Japan and the UK. We use the same set of explanatory variables for the correlation series. For the US stock and bond correlation we observed a positive and significant (including the $10 \%$ level) relation with output growth, inflation, the term structure, stock returns and consumer sentiment. We see the same relation for the stock and bond correlations for Germany, Japan and the UK. A positive and significant (including the 10\% level) is reported for output growth (UK), inflation (all three countries), the term structure (Japan and the UK), stock returns (Germany and the UK) and consumer sentiment (all three countries). Likewise, for the US stock-bond correlation, negative 
predictive power arises from economic policy uncertainty and we see this replicated for Germany and the UK. For the three additional countries, we also see the purchasing managers index having a significant negative predictive relation. As noted above, for the US this coefficient is also negative but only significant at the $11 \%$ level. The change in short term interest rates, which are significantly negative for the US, are negative but not significant for the three additional countries.

Examining the regression results for the same asset correlations, we again see a similar result to that reported for the US. Thus, the coefficient signs reported for the stock-bond correlation are reversed for the bond-bond and stock-stock correlation and are consistent with the US same asset correlations. Therefore, we observe a negative predictive relation arising from the growth rate of industrial production (German and UK bonds and stocks), inflation (German and UK bonds and stocks and Japanese and UK bonds), stock returns (all stock correlations and German and UK bonds) and consumer sentiment (all correlations, except German and Japanese stocks). Likewise, a positive and significant predictive relation arises from the purchasing managers index (all bond correlations and German and UK stocks). In addition, some further significant relations can also be observed but not consistently across multiple regressions.

Across the four countries we can observe a robust set of results. Primarily, the behaviour of the stock and bond correlation and the variables that predict its movement are opposite to the movements of the bond-bond and stock-stock correlations and the variables that predict those movements. Where a variable exhibits a positive relation with the cross-asset correlation, it exhibits a negative relation for the same asset correlation. In terms of the explanatory variables, we can see that inflation plays a key role in determining both cross-asset and same asset correlations as do stock returns, consumer sentiment and the purchasing managers index. The term structure of interest rates also affects the cross-asset correlations and 
US based same asset correlations. Notably, rising inflation, a steepening of the term structure, higher stock returns, an increase in consumer sentiment and a decrease in the purchasing managers index are consistent with a rise in the stock-bond correlation and a fall in the bondbond and stock-stock correlations.

These results are important for both policy-makers and investors, in understanding the transmission of shocks across assets and how the movement of financial assets interacts with the macroeconomy. The results are broadly consistent with the view that indicators of an expanding (contracting) economy lead to a stronger (weaker) cross-asset correlations and weaker (stronger) same asset correlations. Thus, with an expanding economy, markets for the same asset rise at different speeds (reducing their correlation), while the correlation of different assets increases as part of a portfolio. Equally, with a contracting economy, the same assets fall together (raising their correlation), while different assts move in opposite directions (reducing

their correlation). The only exception to that is the purchasing managers index, where a rise in the index indicates greater confidence in future economic conditions on behalf of firms. Here, an examination of stock and bond returns reveals that a positive change in the purchasing managers index is associated with an increase in stock returns and a decrease in bond returns. This perhaps indicates the opposite of a flight-to-safety, where investors are very confident about future economic prospects and the move away from safer bonds towards riskier stocks. Overall, the results support the view that the correlations are driven by investor view of risk. With declining risk associated with falling same asset and rising cross asset correlations and increasing risk with raising same asset and falling cross asset correlations.

\subsection{Portfolio Implications}

The above regression results suggest that a subset of our predictor variables have consistent predictive power across the same asset and cross asset correlations for the international markets 
considered. This raises the prospect that this predictive information can be used to improve portfolio performance. Notably, the stock-bond correlation rises with increases in inflation, consumer sentiment, stock prices and the inverse of the purchasing managers index. Equally, the stock-stock and bond-bond correlation rises with a decrease in the same set of variables. Thus, a portfolio that switches across the different assets could take advantage of the changing nature of the diversification benefits as the correlations change.

To consider the information content of the predictor variables for portfolio performance, we construct a variable that provides an indication of whether the identified variables are signalling an increase in the same asset correlation or an increase in the crossasset correlation. As noted, an increase in inflation, consumer sentiment, stock returns and the negative of the purchasing managers index implies weaker same asset correlations, while a decrease in the same variables implies a weaker cross asset correlation. Thus, our new variable designed to measure the general direction of these four variables is calculated as the per period equally-weighted average of these four standardised variables. We use the standardised variables in order to ensure that each variable has the same scale.

When this correlation indicator variable is greater than zero, this implies that the average of the four variables is positive, which suggest stronger stock-bond correlations and weaker stock-stock and bond-bond correlations. Thus, an investor would obtain greater diversification benefits by investing in cross-country stocks or bonds. In contrast, when our correlation indictor variable is less than zero, this suggests that the predictor variables indicate a falling stock-bond correlation and a rising stock-stock and bond-bond correlation. Thus, an investor would gain greater diversification benefits by investing across both stocks and bonds. Hence, we construct a portfolio that invests equally in the same asset class across countries when the indicator variable is positive and invests equally across stocks and bonds when the indicator variable is negative. Further, when investing in the same asset class across countries, 
we consider portfolios that include and exclude Japan given its lack of an identified predictive relation, while when investing across assets, we consider US stocks and bonds. Furthermore, in constructing the portfolios, we use the lagged value of the indicator variable in order to only use information that would be available to an investor. To provide a comparison to this constructed portfolio, we consider three broad baseline portfolios, a US buy-and-hold, a 60/40 buy-and-hold in favour of stocks and an equally weighted buy-and-hold portfolio for crosscountry same asset portfolios (again, we consider this including and excluding Japan).

The results from constructing these portfolios are reported in Table 4. Our main interest here is comparing the portfolios constructed based on the sign of the correlation predictor indicator against the alternative benchmark portfolios. Examining the stock portfolios, we can see that the US only stock portfolio achieves the highest return and also the highest standard deviation. Nonetheless, on the basis of the Sharpe ratio, the US only stock portfolio outperforms an equally weighted international stock portfolio. A portfolio that combines a $60 \%$ weighting in US stocks and $40 \%$ weighting US bonds achieves a higher Sharpe ratio than any stock only portfolio, while the return is reduced by including bonds, the reduction in the standard deviation is sufficiently large to increase the overall return per unit of standard deviation. The portfolio constructed on the basis of the correlation indicator, however, achieves a higher Sharpe ratio than each of the alternative portfolios. The portfolios constructed here consist of an equally weighted stock portfolio (either including or excluding Japan) when the correlation predictor indicator is positive and an equally weighted stock and bond portfolio when it is negative. This balances the higher return available from the stock portfolio and the reduction in standard deviation from including bonds. A similar overall picture is found when considering bond portfolios, although with some minor differences. Considering the US only bond portfolio against an equally weighted international bond portfolio, the latter outperforms the former in terms of return, standard deviation and the Sharpe ratio (which differs from the 
stock portfolios result). The bond portfolios built on the sign of the correlation indicator again outperform all the other bond portfolios, achieving a higher return and Sharpe ratio. The 60/40 portfolio does achieve a higher Sharpe ratio, although that contains a majority position in stocks and is not comparable to the other bond portfolios.

\section{Summary and Conclusion.}

Using the realised volatility methodology, this paper considers the behaviour of cross-market and cross-asset stock and bond return correlations for the US, the UK, Germany and Japan. Using a set of explanatory variables, we examine whether there is any commonality in the predictive ability of these variables for the cross-asset and cross-market correlations. This paper thus brings together two strands of the literature, one that examines in a descriptive way the movement of cross-asset and cross-country correlations and another that seeks to model (typically) same-asset cross-country correlations. The results here will be of interest not only to academics but also to investors and policy-makers in understanding the linkages between financial markets, which, for investors may help to improve portfolio building and for policymakers may improve their knowledge of information flows and the transmission of shocks.

In common with established results, we report that the correlations for the same asset across international markets (stock-stock and bond-bond) rise over time for the US, the UK and Germany. We also reveal that correlations involving Japanese assets broadly fluctuate around a constant mean, with no obvious direction. Further, we provide evidence that a rising same-asset correlation occurs simultaneously with a falling cross-asset correlation, supporting a previous but less well-established result. In extending the established results and considering a range of explanatory variables, we demonstrate that the variables that exhibit a positive predictive relation with the stock-bond correlation, exhibit a negative predictive correlation with the stock-stock and bond-bond correlations. Thus, driving the correlations in different 
directions. In examining the predictive relations, we note that inflation, stock returns, consumer sentiment and the purchasing managers index provide a consistently significant relation across the correlation series. An increase in the former three are associated with an increase in the cross-asset correlation and a decrease in the same asset correlation, while the converse result is found for the purchasing managers index. With a caveat discussed above regarding this latter variable, these results support the view that when the predictor variables point towards economic expansion the cross-asset correlation increases and the same asset correlation falls. This supports the view that increased economic risk leads to higher same asset correlations through a contagion effect and lower cross-asset correlations through a flight-to-safety effect.

Given the above established patterns in the predictive relation, we then consider whether these results have any implications for portfolio management. We construct a portfolio that is based on a correlation indictor variable according to the sign of the (standardised) predictor variables, investing in either the same asset across international markets or across assets in the same international market when the predictor variables indicate a lower correlation. This portfolio is compared to a series of buy-and-hold portfolios that invest in either a single asset or a fixed combination of assets. The results indicate that a portfolio that invests in the same asset across countries when our indicator variable supports an economic expansion and across assets when the indicator variable indicates a contraction, outperforms the alternative variables.

Overall, this paper shows that variables associated with an economic expansion lead to a higher cross asset correlation and a lower same asst correlation, with the converse also true. Such a result is important for policy-makers in understanding information transmission and for investors in building a diversified portfolio. 


\section{References}

Andersen, T.G. and Bollerslev, T. (1998). Answering the skeptics: Yes, standard volatility models do provide accurate forecasts. International Economic Review, 39, 885-905.

Andersen, T.G., Bollerslev, T., Diebold, F.X. and Labys, P. (2003). Modeling and forecasting realized volatility. Econometrica, 71, 579-625.

Andersson M., Krylova, E. and Vähämaa, S. (2008). Why does the correlation between stock and bond returns vary over time? Applied Financial Economics, 18, 139-151.

Ang, A. and Bekaert, G. (2002). International asset allocation with regime shifts. Review of Financial Studies, $1137-1187$.

Antonakakis, N., Chatziantoniou, I. and Filis, G. (2013). Dynamic co-movements of stock market returns, implied volatility and policy uncertainty. Economics Letters, 120, 87-92.

Aslanidis, N. and Christiansen, C. (2012). Smooth transition patterns in the realized stock-bond correlation. Journal of Empirical Finance, 19, 454-464.

Aslanidis, N. and Christiansen, C. (2014). Quantiles of the realized stock-bond correlation and links to the macroeconomy. Journal of Empirical Finance, 28, 321-331.

Aslanidis, N., Christiansen, C. and Cipollini, A. (2019). Predicting bonds betas using macrofinance variables. Finance Research Letters, 29, 193-199.

Baele, L., Bekaert, G. and Inghelbrecht, K. (2010). The determinants of stock and bond return comovements. Review of Financial Studies, 23, 2374-2428.

Baker, S.R., Bloom, N. and Davis, S.J. (2016). Measuring economic policy uncertainty. Quarterly Journal of Economics, 131, 1593-1636.

Barr, D.G. and Priestley, R., (2004). Expected returns, risk and the integration of international bond markets. Journal of International Money and Finance, 23, 71-97.

Barsky, R. (1989). Why don't the prices of stocks and bonds move together? American Economic Review, 79, 1132-1145.

Baur, D. (2010). Stock-bond co-movements and cross-country linkages. International Journal of Banking, Accounting and Finance, 2, 111-129.

Baur, D. and Lucey, B. (2010). Is gold a hedge or a safe haven? An analysis of stocks, bonds and gold. Finance Review, 45, 217-229.

Bekaert, G. and Harvey, C.R. (1995). Time-varying world market integration. Journal of Finance, 50, 403-444.

Bekaert, G., Harvey, C.R. and Lumsdaine, R.L. (2002). Dating the integration of world equity markets. Journal of Financial Economics, 65, 203-247. 
Bekaert, G., Harvey, C.R. and Ng, A. (2005). Market integration and contagion. Journal of Business, 78, 39-70.

Bollerslev, T. (1986). Generalized autoregressive conditional heteroskedasticity. Journal of Econometrics, 31, 307-327.

Butler, K.C. and Joaquin, D.C. (2002). Are the gains from international portfolio diversification exaggerated? The influence of downside risk in bear markets. Journal of International Money and Finance, 21, 981-1011.

Campbell, J.Y. and Ammer, J. (1993). What moves the stock and bond markets? A variance decomposition for long-term asset returns. Journal of Finance, 48, 3-37.

Campbell, J.Y., Sunderam, A. and Viceira, L.M. (2017). Inflation bets or deflation hedges? The changing risks of nominal bonds. Critical Finance Review, 6, 263-301.

Colacito, R., Engle., R. and Ghysels, E. (2011). A component model for dynamic correlations. Journal of Econometrics, 164, 45-59.

Connolly, R., Stivers, C. and Sun, L. (2005). Stock market uncertainty and the stock-bond return relation. Journal of Financial and Quantitative Analysis, 40, 161-194.

Connolly, R., Stivers, C. and Sun, L. (2007). Commonality in the time variation of stock-bond and stock-stock return comovements. Journal of Financial Markets, 10, 192-218.

Engle, R.F. (1982). Autoregressive conditional heteroscedasticity with estimates of the variance of United Kingdom inflation. Econometrica, 50, 987-1007.

Engle, R.F. (2002). Dynamic conditional correlation - a simple class of multivariate GARCH models. Journal of Business and Economic Statistics, 20, 339-350.

Evans, P. and McMillan, D.G. (2009). Financial co-movement and correlation: Evidence from 33 international stock market indices. International Journal of Banking, Accounting and Finance, 1, 215-241.

Fan, J. and Mitchell, M. (2017). Equity-bond correlation: A historical perspective. Graeme Capital Management Research Note, September, 1-3.

Fisher, K.L. and Statman, M. (2003). Consumer confidence and stock returns. Journal of Portfolio Management, 30, 115-127.

Forbes, K.J. and Rigobon, R. (2002). No contagion, only interdependence: Measuring stock market co-movements. Journal of Finance, 57, 2223-2261.

French, K., Schwert, G.W. and Stambaugh, R. (1987). Expected stock returns and volatility. Journal of Financial Economics, 19, 3-29.

Gulko, L. (2002). Decoupling. Journal of Portfolio Management, 28, 59-66.

Kim, S.-J., Lucey, B.M. and Wu, E. (2006a). Dynamics of bond market integration between 
established and accession European Union countries. Journal of International Financial Markets, Institutions and Money, 16, 41-56.

Kim, S.-J., Moshirian, F. and Wu, E. (2006b). Dynamic stock-bond market integration driven by the European Monetary Union: An empirical analysis. Journal of Banking and Finance, 30, $1507-1534$

Li, L. (2002). Macroeconomic factors and the correlation of stock and bond returns. Yale International Center for Finance Working Paper, No 02-46.

McAleer, M. and Medeiros, M.C. (2008). Realized volatility: A review. Econometric Reviews, $27,10-45$.

McMillan, D.G. (2019). Cross-asset relations, correlations and economic implications. Global Finance Journal, (forthcoming).

Phan, D.H.B., Sharma, S.S. and Tran, V.T. (2018). Can economic policy uncertainty predict stock returns? Global evidence. Journal of International Financial Markets, Institutions and Money, 55, 134-150.

Rankin, E. and Shah Idil, M. (2014). A century of stock-bond correlations. Reserve Bank of Australia Bulletin, September, 67-74.

Schwert, G.W. (1989). Why does stock market volatility change over time? Journal of Finance, 44, 1115-1153.

Shiller, R.J. and Beltratti, A.E. (1992). Stock prices and bond yields: Can their comovements be explained in terms of present value models? Journal of Monetary Economics, 30, 25-46.

Skintzi, V.D. and Refenes, A.N. (2006). Volatility Spillovers and Dynamic Correlation in European Bond Markets. Journal of International Financial Markets, Institutions and Money, $16,23-40$.

Viceira, L.M. (2012). Bond risk, bond return volatility, and the term structure of interest rates. International Journal of Forecasting, 28, 97-117. 
Table 1. Correlation Summary Statistics

\begin{tabular}{|l|l|l|l|l|l|l|}
\hline & Mean & Std Dev & Min & Max & Skew & Kurt \\
\hline & \multicolumn{5}{|c|}{ Stock/Bond Correlation with Same Market } \\
\hline \multicolumn{7}{|c|}{ Bonds Returns } \\
\hline Germany & 0.039 & 0.461 & -0.857 & 0.906 & -0.125 & 1.792 \\
\hline Japan & -0.143 & 0.375 & -0.868 & 0.882 & 0.532 & 2.545 \\
\hline UK & 0.061 & 0.444 & -0.829 & 0.900 & -0.119 & 1.866 \\
\hline US & 0.042 & 0.453 & -0.871 & 0.806 & -0.232 & 1.797 \\
\hline \multicolumn{7}{|c|}{ Stock Return Correlations } \\
\hline US/DE & 0.393 & 0.308 & -0.382 & 0.940 & -0.361 & 2.242 \\
\hline US/JP & 0.112 & 0.213 & -0.420 & 0.846 & -0.005 & 3.112 \\
\hline US/UK & 0.407 & 0.245 & -0.373 & 0.907 & -0.564 & 2.970 \\
\hline UK/DE & 0.569 & 0.292 & -0.530 & 0.963 & -0.813 & 2.917 \\
\hline UK/JP & 0.242 & 0.220 & -0.427 & 0.817 & -0.225 & 3.057 \\
\hline DE/JP & 0.241 & 0.218 & -0.329 & 0.795 & -0.184 & 2.673 \\
\hline \multicolumn{7}{|c|}{ Bond Return Correlations } \\
\hline US/DE & 0.344 & 0.297 & -0.667 & 0.894 & -0.315 & 2.402 \\
\hline US/JP & 0.088 & 0.220 & -0.509 & 0.611 & -0.049 & 2.366 \\
\hline US/UK & 0.418 & 0.267 & -0.538 & 0.872 & -0.708 & 3.180 \\
\hline UK/DE & 0.520 & 0.329 & -0.405 & 0.977 & -0.487 & 2.187 \\
\hline UK/JP & 0.127 & 0.227 & -0.521 & 0.738 & -0.098 & 2.740 \\
\hline DE/JP & 0.192 & 0.216 & -0.451 & 0.850 & -0.297 & 3.203 \\
\hline $\begin{array}{l}\text { Notes: Summary statistics are for German (DE), Japanese (JP), UK and US monthly realised } \\
\text { correlations. }\end{array}$ \\
\hline
\end{tabular}


Table 2. Regressions for US Correlations

\begin{tabular}{|c|c|c|c|c|c|c|c|}
\hline & & \multicolumn{3}{|c|}{ Bond Correlations } & \multicolumn{3}{c|}{ Stock Correlations } \\
\hline & $\mathrm{B} / \mathrm{S}$ & $\mathrm{DE}$ & $\mathrm{JP}$ & $\mathrm{UK}$ & $\mathrm{DE}$ & $\mathrm{JP}$ & $\mathrm{UK}$ \\
\hline$\Delta \mathrm{IP}$ & 0.068 & -0.110 & -0.030 & -0.027 & -0.063 & 0.007 & -0.003 \\
& $(1.75)$ & $(-3.85)$ & $(-1.55)$ & $(-2.23)$ & $(-2.80)$ & $(0.36)$ & $(-0.14)$ \\
\hline$\Delta \mathrm{CPI}$ & 0.267 & -0.179 & -0.015 & -0.183 & -0.213 & -0.005 & -0.109 \\
& $(2.45)$ & $(-3.32)$ & $(-0.45)$ & $(-3.04)$ & $(-3.42)$ & $(-0.10)$ & $(-2.21)$ \\
\hline$\Delta \mathrm{IR}$ & -0.382 & 0.118 & 0.046 & 0.127 & 0.114 & 0.077 & 0.021 \\
& $(-2.87)$ & $(1.11)$ & $(0.51)$ & $(1.34)$ & $(1.34)$ & $(0.88)$ & $(0.22)$ \\
\hline TS & 0.075 & -0.067 & -0.012 & -0.061 & -0.073 & 0.001 & -0.048 \\
& $(1.73)$ & $(-2.39)$ & $(-1.02)$ & $(-2.87)$ & $(-2.69)$ & $(0.10)$ & $(-2.96)$ \\
\hline SR & 0.012 & -0.008 & -0.002 & -0.006 & -0.009 & -0.006 & -0.002 \\
& $(2.40)$ & $(-2.55)$ & $(-0.69)$ & $(-2.07)$ & $(-2.48)$ & $(-3.00)$ & $(-0.63)$ \\
\hline BR & -0.063 & 0.008 & 0.010 & 0.004 & 0.005 & 0.003 & -0.002 \\
& $(-4.28)$ & $(0.71)$ & $(0.82)$ & $(0.43)$ & $(0.47)$ & $(0.32)$ & $(-0.15)$ \\
\hline FCI & 0.063 & -0.134 & -0.031 & -0.124 & -0.003 & -0.021 & 0.048 \\
& $(0.67)$ & $(-2.03)$ & $(-0.11)$ & $(-2.23)$ & $(-0.04)$ & $(-0.78)$ & $(1.15)$ \\
\hline Cons & 0.013 & -0.010 & -0.001 & -0.005 & -0.010 & 0.001 & -0.005 \\
Sent & $(3.00)$ & $(-4.40)$ & $(-0.78)$ & $(-3.04)$ & $(-4.14)$ & $(0.60)$ & $(-3.57)$ \\
\hline PMI & -0.012 & 0.014 & 0.001 & 0.009 & 0.016 & 0.001 & 0.012 \\
& $(-1.62)$ & $(2.64)$ & $(0.19)$ & $(2.17)$ & $(2.83)$ & $(0.39)$ & $(2.63)$ \\
\hline EPU & -0.003 & 0.001 & 0.001 & 0.001 & 0.001 & 0.001 & 0.001 \\
& $(-2.02)$ & $(1.61)$ & $(0.91)$ & $(1.45)$ & $(1.36)$ & $(2.66)$ & $(2.63)$ \\
\hline R-sq & 0.206 & 0.193 & 0.016 & 0.117 & 0.202 & 0.040 & 0.140 \\
\hline
\end{tabular}

Notes: Entries are coefficients and Newey-West $t$-statistics for the regression in equation (4). The dependent variables are the correlations between US stock and bond returns $(\mathrm{B} / \mathrm{S})$ and bond and stock returns between the US, Germany (DE), Japan (JP) and the UK. The explanatory variables are the monthly change in industrial production $(\Delta \mathrm{IP})$, the monthly change in the consumer price index ( $\triangle \mathrm{CPI}$, inflation), the monthly change in short-term interest rates $(\Delta I R)$, the term structure of interest rates (TS), stock returns (SR), bond returns (BR), the financial conditions index (FCI), consumer sentiment (Cons Sent), purchasing managers index (PMI) and economic policy uncertainty (EPU). 
Table 3. Regression for Additional Countries

\begin{tabular}{|c|c|c|c|c|c|c|}
\hline & \multicolumn{6}{|c|}{ Bond / Stock Correlations } \\
\hline & \multicolumn{2}{|c|}{ Germany } & \multicolumn{2}{|c|}{ Japan } & \multicolumn{2}{|c|}{ UK } \\
\hline$\Delta \mathrm{IP}$ & \multicolumn{2}{|c|}{$\begin{array}{l}0.036 \\
(1.05)\end{array}$} & \multicolumn{2}{|c|}{$\begin{array}{l}0.052 \\
(1.57)\end{array}$} & \multicolumn{2}{|c|}{$\begin{array}{l}0.075 \\
(2.38)\end{array}$} \\
\hline$\Delta \mathrm{CPI}$ & \multicolumn{2}{|c|}{$\begin{array}{l}0.209 \\
(1.77)\end{array}$} & \multicolumn{2}{|c|}{$\begin{array}{l}0.247 \\
(2.69)\end{array}$} & \multicolumn{2}{|c|}{$\begin{array}{l}0.240 \\
(2.38)\end{array}$} \\
\hline$\Delta \mathrm{IR}$ & \multicolumn{2}{|c|}{$\begin{array}{l}-0.192 \\
(-1.42)\end{array}$} & \multicolumn{2}{|c|}{$\begin{array}{l}-0.161 \\
(-1.22)\end{array}$} & \multicolumn{2}{|c|}{$\begin{array}{l}-0.131 \\
(-1.04)\end{array}$} \\
\hline TS & \multicolumn{2}{|c|}{$\begin{array}{l}0.065 \\
(1.39)\end{array}$} & \multicolumn{2}{|c|}{$\begin{array}{l}0.066 \\
(2.06)\end{array}$} & \multicolumn{2}{|c|}{$\begin{array}{l}0.072 \\
(1.67)\end{array}$} \\
\hline SR & \multicolumn{2}{|c|}{$\begin{array}{l}0.012 \\
(2.28)\end{array}$} & \multicolumn{2}{|c|}{$\begin{array}{l}0.006 \\
(1.43)\end{array}$} & \multicolumn{2}{|c|}{$\begin{array}{l}0.018 \\
(3.55)\end{array}$} \\
\hline BR & \multicolumn{2}{|c|}{$\begin{array}{l}-0.028 \\
(-1.68)\end{array}$} & \multicolumn{2}{|c|}{$\begin{array}{l}-0.013 \\
(0.81)\end{array}$} & \multicolumn{2}{|c|}{$\begin{array}{l}-0.017 \\
(-1.25)\end{array}$} \\
\hline FCI & \multicolumn{2}{|c|}{$\begin{array}{l}-0.112 \\
(-1.12)\end{array}$} & \multicolumn{2}{|c|}{$\begin{array}{l}0.027 \\
(0.29)\end{array}$} & \multicolumn{2}{|c|}{$\begin{array}{l}0.001 \\
(0.01)\end{array}$} \\
\hline Cons Sent & \multicolumn{2}{|c|}{$\begin{array}{l}0.010 \\
(2.76)\end{array}$} & \multicolumn{2}{|c|}{$\begin{array}{l}0.009 \\
(3.22)\end{array}$} & \multicolumn{2}{|c|}{$\begin{array}{l}0.010 \\
(2.52)\end{array}$} \\
\hline PMI & \multicolumn{2}{|c|}{$\begin{array}{l}-0.026 \\
(-2.45)\end{array}$} & \multicolumn{2}{|c|}{$\begin{array}{l}-0.027 \\
(-3.41)\end{array}$} & \multicolumn{2}{|c|}{$\begin{array}{l}-0.016 \\
(-1.90)\end{array}$} \\
\hline EPU & \multicolumn{2}{|c|}{$\begin{array}{l}-0.002 \\
(-1.94)\end{array}$} & \multicolumn{2}{|c|}{$\begin{array}{l}0.001 \\
(0.68)\end{array}$} & & \\
\hline R-sq & & & & & & \\
\hline & & d Correla & & & x Correla & \\
\hline & $\mathrm{DE} / \mathrm{JP}$ & DE/UK & JP/UK & $\mathrm{DE} / \mathrm{JP}$ & DE/UK & JP/UK \\
\hline$\Delta \mathrm{IP}$ & $\begin{array}{l}0.005 \\
(0.32) \\
\end{array}$ & $\begin{array}{l}-0.106 \\
(-3.91) \\
\end{array}$ & $\begin{array}{l}0.001 \\
(0.01)\end{array}$ & $\begin{array}{l}-0.014 \\
(-0.80) \\
\end{array}$ & $\begin{array}{l}-0.054 \\
(-1.98) \\
\end{array}$ & $\begin{array}{l}-0.022 \\
(-1.10) \\
\end{array}$ \\
\hline$\Delta \mathrm{CPI}$ & $\begin{array}{l}-0.004 \\
(-0.08)\end{array}$ & $\begin{array}{l}-0.257 \\
(-3.85)\end{array}$ & $\begin{array}{l}-0.095 \\
(-2.59) \\
\end{array}$ & $\begin{array}{l}0.029 \\
(0.69)\end{array}$ & $\begin{array}{l}-0.233 \\
(-4.18)\end{array}$ & $\begin{array}{l}-0.031 \\
(-0.71)\end{array}$ \\
\hline$\Delta \mathrm{IR}$ & $\begin{array}{c}0.031 \\
(0.37)\end{array}$ & $\begin{array}{l}0.126 \\
(1.37)\end{array}$ & $\begin{array}{l}-0.005 \\
(-0.06)\end{array}$ & $\begin{array}{l}-0.007 \\
(-0.10)\end{array}$ & $\begin{array}{l}0.187 \\
(1.74)\end{array}$ & $\begin{array}{l}0.193 \\
(2.41)\end{array}$ \\
\hline TS & $\begin{array}{l}-0.015 \\
(-1.32) \\
\end{array}$ & $\begin{array}{c}-0.052 \\
(-1.58) \\
\end{array}$ & $\begin{array}{l}-0.012 \\
(-1.02) \\
\end{array}$ & $\begin{array}{l}0.001 \\
(0.11) \\
\end{array}$ & $\begin{array}{l}-0.067 \\
(-2.93) \\
\end{array}$ & $\begin{array}{l}-0.018 \\
(-1.26) \\
\end{array}$ \\
\hline SR & $\begin{array}{l}-0.001 \\
(-0.38)\end{array}$ & $\begin{array}{l}-0.012 \\
(-3.47)\end{array}$ & $\begin{array}{l}-0.002 \\
(-0.87)\end{array}$ & $\begin{array}{l}-0.007 \\
(-3.02)\end{array}$ & $\begin{array}{l}-0.009 \\
(-2.79)\end{array}$ & $\begin{array}{l}-0.007 \\
(-2.84) \\
\end{array}$ \\
\hline BR & $\begin{array}{l}0.005 \\
(0.53) \\
\end{array}$ & $\begin{array}{c}0.009 \\
(0.79) \\
\end{array}$ & $\begin{array}{l}0.004 \\
(0.36)\end{array}$ & $\begin{array}{l}0.007 \\
(0.71)\end{array}$ & $\begin{array}{l}0.016 \\
(1.49)\end{array}$ & $\begin{array}{l}0.021 \\
(1.92)\end{array}$ \\
\hline FCI & $\begin{array}{l}-0.006 \\
(-0.20)\end{array}$ & $\begin{array}{l}-0.164 \\
(-2.36)\end{array}$ & $\begin{array}{l}-0.001 \\
(-0.04)\end{array}$ & $\begin{array}{l}-0.011 \\
(-0.29)\end{array}$ & $\begin{array}{l}-0.053 \\
(-0.81)\end{array}$ & $\begin{array}{l}-0.009 \\
(-0.32)\end{array}$ \\
\hline Cons Sent & $\begin{array}{l}-0.003 \\
(-2.15)\end{array}$ & $\begin{array}{l}-0.012 \\
(-4.73)\end{array}$ & $\begin{array}{l}-0.004 \\
(-2.83) \\
\end{array}$ & $\begin{array}{l}0.001 \\
(0.01)\end{array}$ & $\begin{array}{l}-0.011 \\
(-4.77)\end{array}$ & $\begin{array}{l}-0.003 \\
(-1.99) \\
\end{array}$ \\
\hline PMI & $\begin{array}{c}0.005 \\
(1.80) \\
\end{array}$ & $\begin{array}{l}0.013 \\
(1.86)\end{array}$ & $\begin{array}{l}0.006 \\
(2.09)\end{array}$ & $\begin{array}{l}0.003 \\
(0.73) \\
\end{array}$ & $\begin{array}{l}0.010 \\
(1.92)\end{array}$ & $\begin{array}{l}0.004 \\
(1.05)\end{array}$ \\
\hline EPU & $\begin{array}{c}0.001 \\
(0.74)\end{array}$ & $\begin{array}{l}0.001 \\
(0.66)\end{array}$ & $\begin{array}{l}-0.001 \\
(-0.29)\end{array}$ & $\begin{array}{l}-0.001 \\
(-0.85)\end{array}$ & $\begin{array}{l}-0.001 \\
(-1.32)\end{array}$ & $\begin{array}{l}-0.001 \\
(-1.02)\end{array}$ \\
\hline R-sq & 0.033 & 0.218 & 0.048 & 0.034 & 0.194 & 0.044 \\
\hline
\end{tabular}


Table 4. Portfolio Performance

\begin{tabular}{|c|c|c|c|c|c|c|}
\hline & US & $60 / 40$ & EW & EW X J & Indicator & Indic. X J \\
\hline & Stocks & & & & & \\
\hline Mean & 0.7255 & 0.4733 & 0.4736 & 0.6333 & 0.6401 & 0.6641 \\
\hline SD & 4.2995 & 2.7776 & 3.1340 & 4.1720 & 3.0419 & 3.1653 \\
\hline SR & 0.1687 & 0.1703 & 0.1511 & 0.1518 & 0.2104 & 0.2098 \\
\hline & Bonds & & & & & \\
\hline Mean & 0.0951 & 0.4733 & 0.1127 & 0.1459 & 0.2678 & 0.2549 \\
\hline SD & 2.3750 & 2.7776 & 1.2896 & 1.8194 & 2.0460 & 2.1502 \\
\hline SR & 0.0400 & 0.1703 & 0.0874 & 0.0802 & 0.1309 & 0.1185 \\
\hline
\end{tabular}

Notes: Entries are the mean, standard deviation (SD) and Sharpe ratio (SR, the mean dividend by the SD) of the portfolios constructed as: US - buy-and-hold the US asset only; $60 / 40$ - buy-and-hold a portfolio containing 60\% US stocks and 40\% US bonds; EW - an equally weighted portfolio of all four assets; EW X J - an equally weighted portfolio of all assets excluding Japan; Indicator - a portfolio constructed according to the correlation indicator, holding an equally weighted portfolio of the four assets when the indicator is positive and holding an equally weighted portfolio of US stocks and bonds when the indicator is negative; Indic. $\mathrm{X} \mathbf{J}-$ a portfolio constructed according to the correlation indicator, holding an equally weighted portfolio of the assets excluding Japan when the indicator is positive and holding an equally weighted portfolio of US stocks and bonds when the indicator is negative. 
Figure 1. Realised Correlations
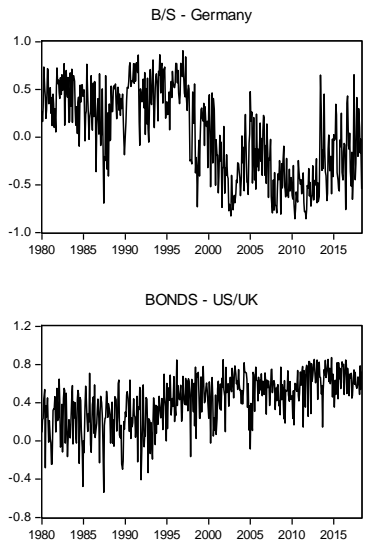

BONDS - US/BD

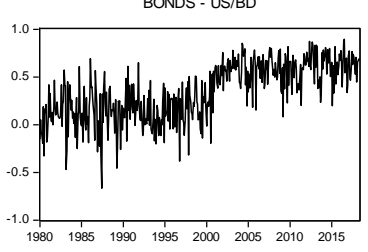

STOCKS - UK/BD

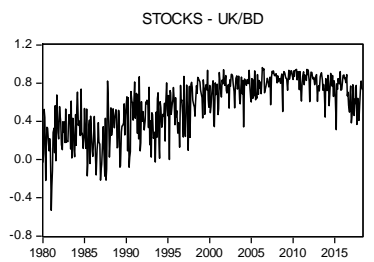

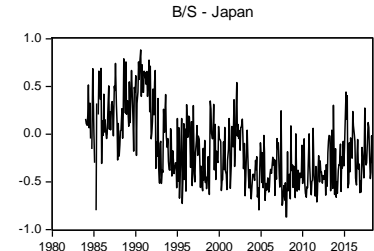

BONDS - JP/BD

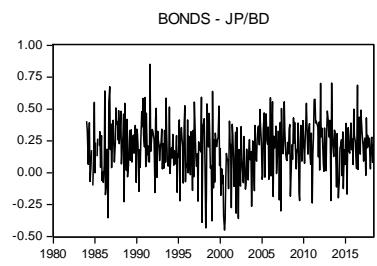

BONDS - US/JP

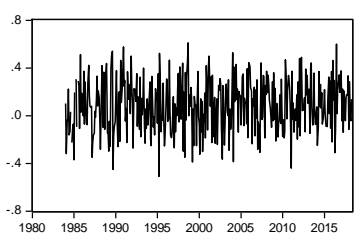

STOCKS - UK/JP

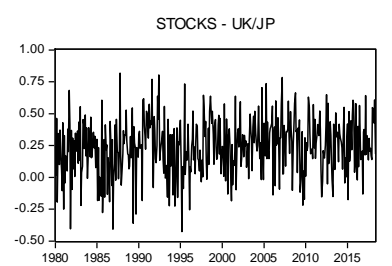

$B / S-U K$

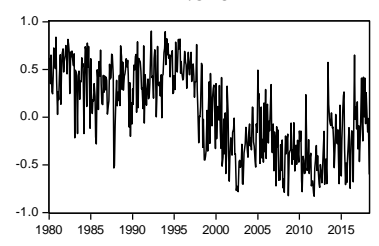

BONDS - UK/BD

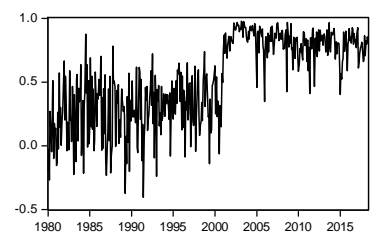

STOCKS - US/UK

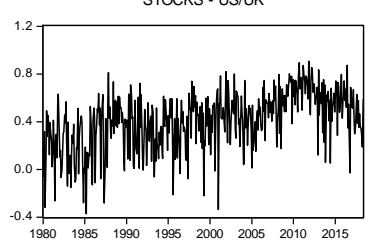

STOCKS - US/BD

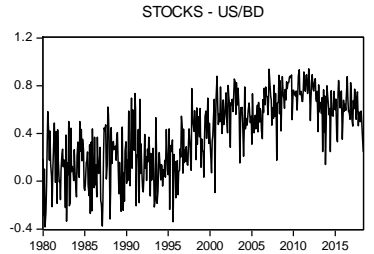

$B / S$ - US
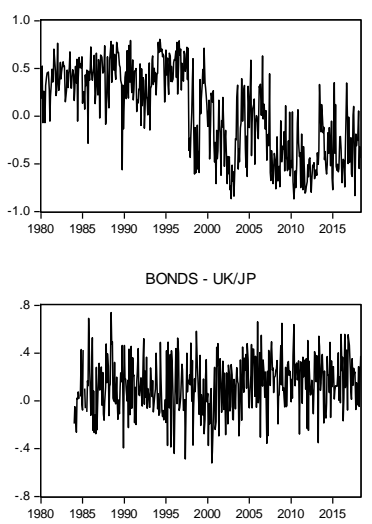

STOCKS - JP/BD

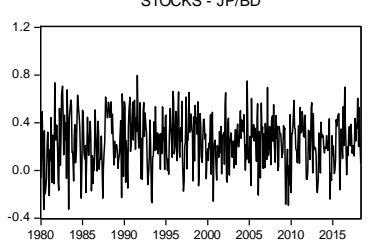

STOCKS - US/JP

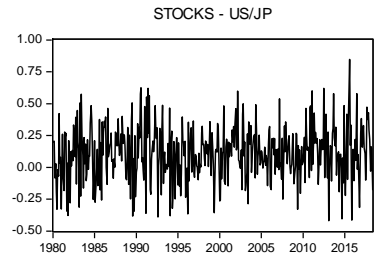


Figure 2. Explanatory Variables

Monthly Change in IP

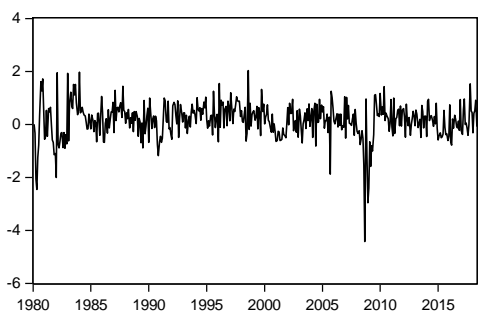

10Y TB - 3M TB

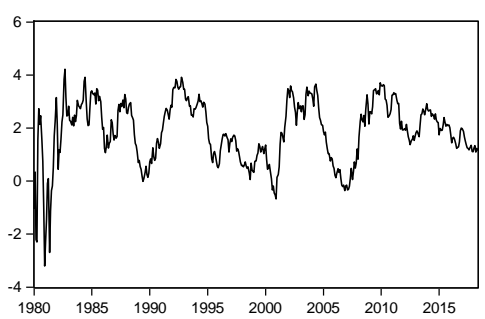

PMI

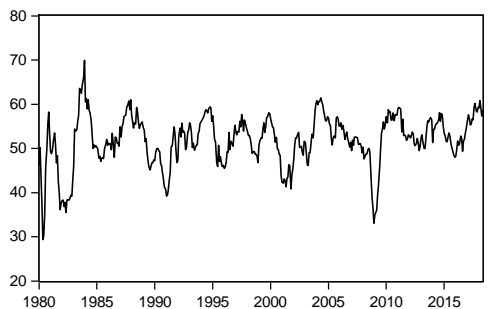

Monthly Change in CPI

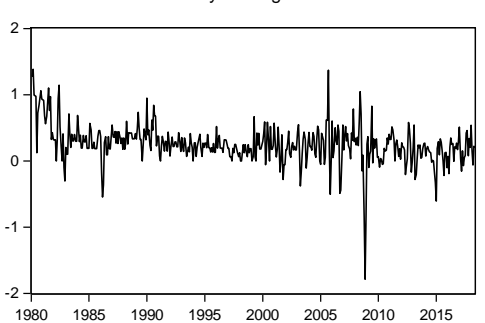

$\mathrm{FCl}$

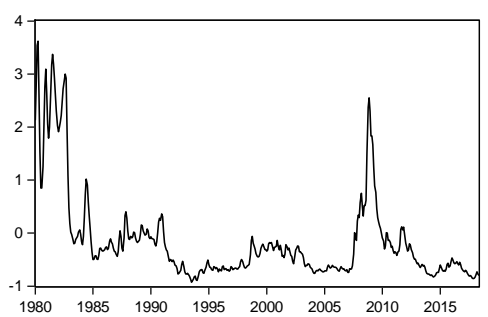

EPU

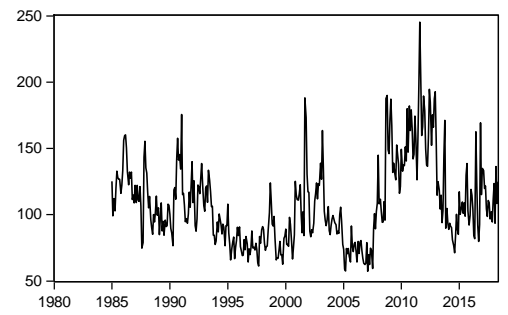

Monthly Change in 10Y TB

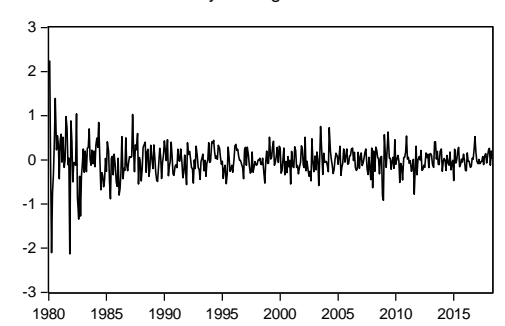

Consumer Sentiment

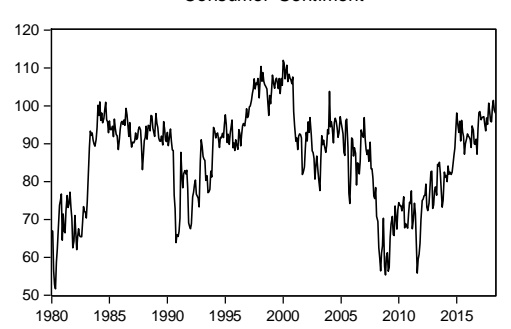

